Article

\title{
Liquid Phase Hydrogenation of Pharmaceutical Interest Nitroarenes over Gold-Supported Alumina Nanowires Catalysts
}

\author{
Krishnamoorthy Shanmugaraj ${ }^{1}$ (D), Tatiana M. Bustamante ${ }^{1}$, Cristian H. Campos ${ }^{1}(\mathbb{D}$ \\ and Cecilia C. Torres ${ }^{2, *(D)}$ \\ 1 Departamento de Físico-Química, Facultad de Ciencias Químicas, Universidad de Concepción, Edmundo \\ Larenas 129, Concepción 4070371, Chile; shanmugaraj.chemist@gmail.com (K.S.); \\ tatibustamante@udec.cl (T.M.B.); ccampos@udec.cl (C.H.C.) \\ 2 Departamento de Química, Facultad de Ciencias Exactas, Universidad Andres Bello, Sede Concepción, \\ Autopista Concepción-Talcahuano 7100, Talcahuano 4300866, Chile \\ * Correspondence: cecilia.torres@unab.cl; Tel.: +56-41-2662151
}

Received: 26 November 2019; Accepted: 10 February 2020; Published: 19 February 2020

\begin{abstract}
In this work, $\mathrm{Au}$ nanoparticles, supported in $\mathrm{Al}_{2} \mathrm{O}_{3}$ nanowires (ANW) modified with (3-aminopropyl)trimethoxysilane were synthetized, for their use as catalysts in the hydrogenation reaction of 4-(2-fluoro-4-nitrophenyl)-morpholine and 4-(4-nitrophenyl)morpholin-3-one. ANW was obtained by hydrothermal techniques and the metal was incorporated by the reduction of the precursor with $\mathrm{NaBH}_{4}$ posterior to superficial modification. The catalysts were prepared at different metal loadings and were characterized by different techniques. The characterization revealed structured materials in the form of nanowires and a successful superficial modification. All catalysts show that $\mathrm{Au}$ is in a reduced state and the shape of the nanoparticles is spherical, with high metal dispersion and size distributions from 3.7 to $4.6 \mathrm{~nm}$. The different systems supported in modified-ANW were active and selective in the hydrogenation reaction of both substrates, finding for all catalytic systems a selectivity of almost $100 \%$ to the aromatic amine. Catalytic data showed pseudo first-order kinetics with respect to the substrate for all experimental conditions used in this work. The solvent plays an important role in the activity and selectivity of the catalyst, where the highest efficiency and operational stability was achieved when ethanol was used as the solvent.
\end{abstract}

Keywords: nanowires; gold; nitroarenes; Aluminium oxide

\section{Introduction}

The catalytic hydrogenation of nitroarenes $\left(-\mathrm{NO}_{2}\right)$ is one of the most important organic reactions for the preparation of amines $\left(-\mathrm{NH}_{2}\right)$, since they are used as intermediates or precursors in the synthesis of drugs, agrochemicals, dyes and other organic compounds [1-5]. The traditional methods for preparing these compounds involve the use of dangerous reducing agents and/or contaminants, such as $\mathrm{N}_{2} \mathrm{H}_{4}, \mathrm{Na}_{2} \mathrm{~S}$, silyl hydrides, in situ $\mathrm{H}_{2}$ generation, among others [2,6]. For example, the used of direct metal produces $\mathrm{H}_{2}$ by reacting with water or by electron-transfer reaction with water acting as proton source. Hydrazine hydrate methodologies release $\mathrm{H}_{2}$ by decomposition facilitating the reduction process. However, these strategies present notable disadvantages such as high reaction temperatures, poor chemoselectivity over other functional groups and lower yield to the desire product due to a mixture of products $[7,8]$. In this context, heterogeneous catalysis is an alternative to these procedures, because these reactions can be highly selective, efficient, environmentally friendly and cheaper, since the catalyst can often be recovered and recycled [2]. In addition, it is noteworthy that 
mild experimental conditions can be modulated in the hydrogenation reaction at lower or atmospheric pressure depending on the catalyst and the nitroarene $[9,10]$.

Gold $(\mathrm{Au})$ as an active phase has shown to be the most selective metal in the hydrogenation of multifunctional nitroarenes [11-18]. Nevertheless, one of the main challenges in the preparation of Au-based catalysts has been the control of particle size to generate active, selective and operationally stable systems in the hydrogenation of nitroarenes [19]. Some strategies consider the preparation of nanometric catalysts, obtained from core-shell (0D) structures that include in their design the insertion of the active phase in the core [20-22] or the Shell [23]. Other reported strategies include the preparation of supported catalysts by the deposition of $\mathrm{Au}$ in support via $1 \mathrm{D}$ arrangements (nanotubes, nanowires) [18,24-26], 2D (graphene sheets, clays) [27-29], or in 3D structures such as mesostructured silicas [16,30,31], carbonaceous supports [32-34] and others.

Alumina is widely used as a heterogeneous catalyst support due to its attractive proprieties mainly due to their high mechanical and thermal stability $[35,36]$. The use of $\gamma-\mathrm{Al}_{2} \mathrm{O}_{3}$ as a nanosupport with high mesoporosity is considered one of the most efficient strategies to achieve efficient mass transport and, therefore, high catalytic performance in heterogeneous catalysis [37-40]. One of the simplest and most reproducible methodologies to obtain $\gamma-\mathrm{Al}_{2} \mathrm{O}_{3}$ with hierarchical porosities is reported by Lu et al., where it is possible to obtain nanowires (NW) with high mesoporosity and specific surface areas $\left(\mathrm{S}_{\mathrm{BET}}\right)$ in the order of $200 \mathrm{~m}^{2} \mathrm{~g}^{-1}$ [41].

As mentioned, nitrocompounds are building blocks for many products of industrial interest and gold supported $\mathrm{Al}_{2} \mathrm{O}_{3}$ catalyst has been applied for different nitroarenes hydrogenation. Wang et al. reach high selectivity for $p$-chloronitrobenzene and Yakushkin et al. obtained chemoselective hydrogenation of 3-nitrostyrene and 4-nitroacetophenone [42-44]. However, more complexes nitroarenes such as 4-(4-nitrophenyl)-morpholine derivates (see Scheme 1) are mostly obtained through traditional synthesis pathways and did not report kinetic data [45]. Only a few report exploring molecules with pharmaceutical applications has been published. Gardiner et al. used catalytic static mixers coated with Pd to obtain 3-fluoro-4-morpholinoaniline (Yield prod $<30 \%$ ) [46]. Bustamante et al. employ Pd-Co catalysts to study a series of halonitroarenes under soft hydrogenation conditions (ethanol as solvent, $80^{\circ} \mathrm{C}$ and 20 bar of $\mathrm{H}_{2}$ pressure) with selectivity to the desired aniline greater than 95\% [47].

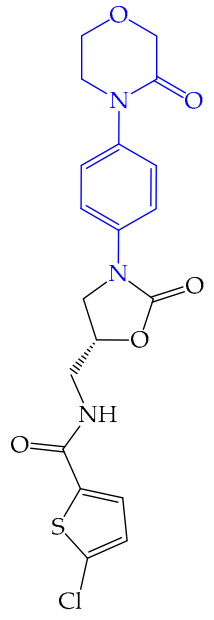

Linezolid

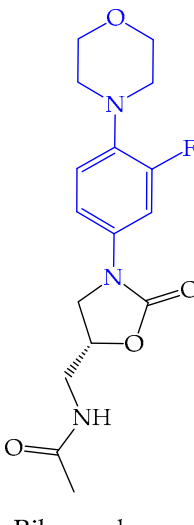

Riboraxaban

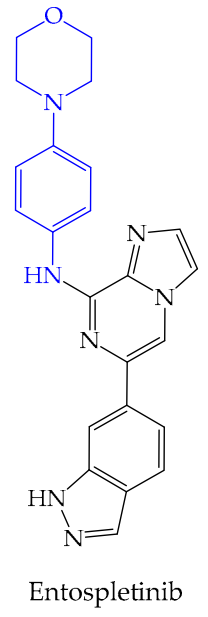

Entospletinib

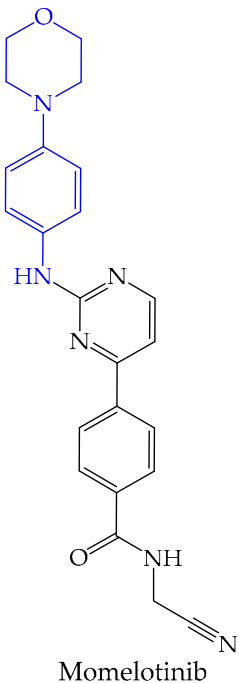

Momelotinib

Scheme 1. The 4-morpholinoaniline derivate drugs: the antimicrobial Linezolid (Zyvox), the anticoagulant blood thinner Rivaroxaban (Xarelto) and the investigational antineoplastic drugs Entospletinib and Momelotinib.

The focus of this work is on the synthesis, characterization and catalytic evaluation of nanocatalysts prepared from the deposition of $\mathrm{Au}$ nanoparticles in supports of $\gamma-\mathrm{Al}_{2} \mathrm{O}_{3}$ type NW (ANW), to be evaluated in the chemoselective hydrogenation of nitroarenes of pharmaceutical interest. The catalysts 
were prepared in different nominal metal loadings: $0.25,0.50$ and $1.00 \mathrm{Au} \mathrm{wt} \%$. All the catalysts were evaluated in the catalytic hydrogenation of 4-(2-fluoro-4-nitrophenyl)-morpholine (NFMF) and 4-(4-nitrophenyl)-3-morpholinone (NFMO) used as intermediates in the synthesis of linezolid (antibiotic action) and rivaroxaban (anticoagulant action), respectively $[48,49]$. In both molecules, different operational conditions were evaluated to produce the respective aren-anilines. For the best catalyst, operational stability was evaluated under optimized hydrogenation conditions. This report presents for the first time the hydrogenation reaction of pharmaceuticals interest molecules and reutilized $\mathrm{Au} / \mathrm{ANW}$ as a new alternative to produce reactions intermediates of drugs.

\section{Materials and Methods}

\subsection{Materials}

$\mathrm{Al}\left(\mathrm{NO}_{3}\right)_{3} \cdot 9 \mathrm{H}_{2} \mathrm{O},(1 \mathrm{R})$-(-)-camphorsulfonic acid (CSA, 98\%), (3-Aminopropyl)trimethoxysilane (APTMS, $\geq 98 \%$ ), morpholine, $\mathrm{N}, \mathrm{N}$-diisopropylethylamine, acetonitrile, methanol, toluene, absolute ethanol, ethyl acetate, dichloromethane, chloroform, tetrahydrofurane (THF), hexane, $\mathrm{HNO}_{3}$ $(67 \%)$, and $\mathrm{HCl}(37 \%), \mathrm{Na}_{2} \mathrm{SO}_{4}$ anhydrous, potassium permanganate, sodium bisulfite, aqueous ammonia solution $\left(\mathrm{NH}_{4} \mathrm{OH} 37 \%\right.$ ) and $\mathrm{HAuCl}_{4} \cdot 3 \mathrm{H}_{2} \mathrm{O}$ were provided by Merck (Darmstadt, Germany). Benzyltrimethylammoniun chloride and 4-phenylmorpholine were provided by Sigma-Aldrich (Darmstadt, Germany). Toluene was dried over metallic sodium before use. All other reagents were used without further purification. $\mathrm{H}_{2}(99.99 \%)$, $\mathrm{He}(99.99 \%)$, synthetic air, and $\mathrm{N}_{2}$ were provided by Linde Chile (Concepción, Chile).

\subsection{Synthesis of the Substrates}

The drug precursors 4-(2-fluoro-4-nitrophenyl)morpholine and 4-(4-nitrophenyl)morpholin-3-one could not be sourced from commercial suppliers, so they were synthesized and characterized as detailed.

\subsubsection{Synthesis of 4-(2-fluoro-4-nitrophenyl)morpholine}

3,4-difluoronitrobenzene $(3.0 \mathrm{~mL}, 4.31 \mathrm{~g}, 27.1 \mathrm{mmol})$ was added to a mixture of morpholine $(4.72 \mathrm{~mL}, 4.72 \mathrm{~g}, 54.2 \mathrm{mmol})$ and $\mathrm{N}, \mathrm{N}$-diisopropylethylamine $(9.44 \mathrm{~g}, 54.2 \mathrm{mmol})$ in acetonitrile $(27 \mathrm{~mL})$, and the resulting mixture was stirred at room temperature for $48 \mathrm{~h}$. The final solution was dried and dissolved in ethyl acetate. The product was washed with water $(3 x)$ and brine. The organic layer was separated and dried over $\mathrm{Na}_{2} \mathrm{SO}_{4}$, filtered, and concentrated under vacuum to give a yellow solid (6.32 g, ca. 98\%). ${ }^{1} \mathrm{H}$ NMR (400 MHz, $\left.\mathrm{CDCl}_{3}\right) \delta: 7.93(1 \mathrm{H}, \mathrm{d}, \mathrm{J}=7.5 \mathrm{~Hz}), 7.84(1 \mathrm{H}, \mathrm{d}, \mathrm{J}=10.5 \mathrm{~Hz}), 6.89$ $(1 \mathrm{H}, \mathrm{t}, \mathrm{J}=8.0 \mathrm{~Hz}), 3.84(4 \mathrm{H}, \mathrm{t}, \mathrm{J}=5.0 \mathrm{~Hz}), 3.25(4 \mathrm{H}, \mathrm{t}, \mathrm{J}=9.5 \mathrm{~Hz}) \mathrm{ppm} .{ }^{13} \mathrm{C} \mathrm{NMR}\left(75 \mathrm{MHz}, \mathrm{CDCl}_{3}\right) \delta$ : $50.0,66.7,112.7,117.0,121.1,140.8,145.6,152.2-154.2 \mathrm{ppm}$.

\subsubsection{Synthesis of 4-(4-nitrophenyl)morpholin-3-one}

The synthesis of 4-(4-nitrophenyl)morpholin-3-one was carried out by two steps of synthesis as shown in Scheme 2. In step one, the intermediary was prepared following synthesis, as reported by Markgraf et al. [50]. Finely ground potassium permanganate $(0.474 \mathrm{~g}, 3.00 \mathrm{mmol})$ was added to a stirred solution of the 4-phenylmorpholine $(0.326 \mathrm{~g}, 2.00 \mathrm{mmol})$ and benzyltrimethylammoniun chloride $(0.683 \mathrm{~g}, 3.00 \mathrm{mmol})$ in dichloromethane $(10 \mathrm{~mL})$, and the purple solution was stirred at reflux for $3 \mathrm{~h}$.

The mixture was cooled in ice and a solution of sodium bisulfite $(2 \mathrm{~g})$ in water $(10 \mathrm{~mL})$ was added and separated; the aqueous phase was extracted with chloroform $(3 \times 10 \mathrm{~mL})$. The combined organic extract was washed with water $(20 \mathrm{~mL})$ and dried with $\mathrm{Na}_{2} \mathrm{SO}_{4}$. The solvent removal gave a residual yellow solid ( $0.205 \mathrm{~g}$, $56 \%$ yield) which was recrystallized from hexane to give 4-phenylmorpholin-3-one (0.135 g, 35\% yield). ${ }^{1} \mathrm{H}$ NMR $\left(400 \mathrm{MHz}, \mathrm{CDCl}_{3}\right) \delta 7.41(2 \mathrm{H}, \mathrm{m}) .7 .31(3 \mathrm{H}, \mathrm{m}), 4.34(2 \mathrm{H}, \mathrm{s}), 4.02(2 \mathrm{H}$, app t, J = 5.0 Hz), $\delta 3.76\left(2 \mathrm{H}\right.$, app t, J = 5.0 Hz) ppm. ${ }^{13} \mathrm{C} \mathrm{NMR}\left(75 \mathrm{MHz}, \mathrm{CDCl}_{3}\right): \delta 49.7,64.2,68.6$, $125.6,127.2,129.4,141.4,166.7 \mathrm{ppm}$. 


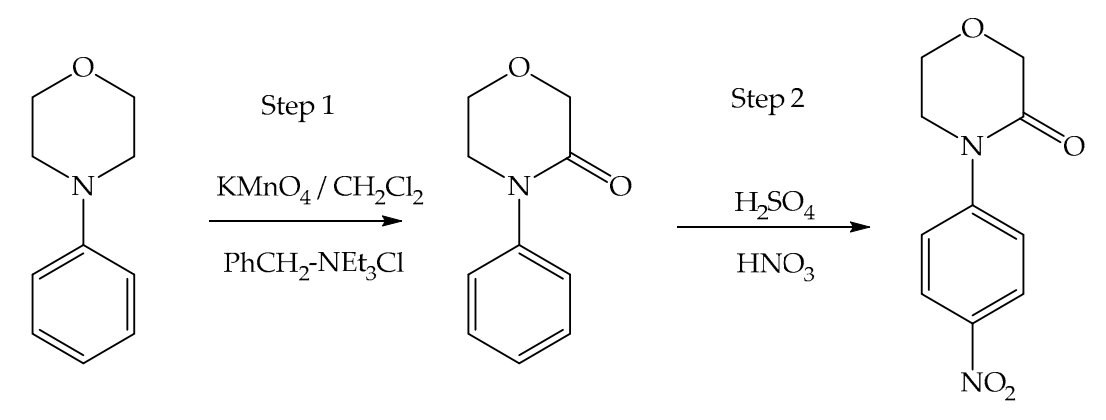

Scheme 2. Synthetic pathway for the preparation of 4-(4-nitrophenyl)morpholin-3-one.

The second step was carried out following the experimental methodology reported by Xing et al. [49]. To a solution of 4-phenylmorpholin-3-one $(0.995 \mathrm{~g}, 5.62 \mathrm{~mol})$ at $98 \%, \mathrm{H}_{2} \mathrm{SO}_{4}(2.33 \mathrm{~mL})$ cooled to $-10{ }^{\circ} \mathrm{C} 65 \% \mathrm{HNO}_{3}$ was carefully added dropwise $(0.4 \mathrm{~mL})$ over $45 \mathrm{~min}$. The reddish solution obtained was stirred at this temperature for $1 \mathrm{~h}$ and $\mathrm{H}_{2} \mathrm{O}(5 \mathrm{~mL})$ was added. The mixture was neutralized with $35 \% \mathrm{NH}_{4} \mathrm{OH}$ until $\mathrm{pH} 7$. The resulting precipitate was filtered, washed with cold water and dried, resulting in the desired product $\left(1.01 \mathrm{~g}, 83 \%\right.$ yield) as a brown solid. ${ }^{1} \mathrm{H}$ NMR $\left(400 \mathrm{MHz}, \mathrm{CDCl}_{3}\right) \delta: 8.27(2 \mathrm{H}, \mathrm{d}, \mathrm{J}=9.4 \mathrm{~Hz}),, 7.62(2 \mathrm{H}, \mathrm{d}, \mathrm{J}=9.4 \mathrm{~Hz}), 4.38(2 \mathrm{H}, \mathrm{s}), 4.08(2 \mathrm{H}, \mathrm{t}, \mathrm{J}=5.0 \mathrm{~Hz})$, $3.85(2 \mathrm{H}, \mathrm{t}, \mathrm{J}=5.0 \mathrm{~Hz}) \mathrm{ppm} .{ }^{13} \mathrm{C} \mathrm{NMR}\left(75 \mathrm{MHz}, \mathrm{CDCl}_{3}\right): \delta 49.6,64.2,68.6,124.2,125.6,145.4,146.4$, $167.4 \mathrm{ppm}$.

\section{3. $\mathrm{Al}_{2} \mathrm{O}_{3}$ Nanowires (ANW) and Catalysts Synthesis}

The synthesis of the ANW was carried out by a method previously reported by our research group with some modifications [51]. Twenty-two grams of $\mathrm{Al}\left(\mathrm{NO}_{3}\right)_{3} \cdot 9 \mathrm{H}_{2} \mathrm{O}$ were dissolved together with $2.2 \mathrm{~g}$ of CSA as a surfactant, in $160 \mathrm{~mL}$ of distilled $\mathrm{H}_{2} \mathrm{O}$, and kept under magnetic stirring. The mixture was brought to $\mathrm{pH} 5.4$ using $\mathrm{NH}_{4} \mathrm{OH}$, forming a white gel which was kept under stirring for $10 \mathrm{~min}$. Subsequently, the gel was transferred into a stainless-steel autoclave coated with teflon and held for $72 \mathrm{~h}$ at $160^{\circ} \mathrm{C}$. It was then allowed to cool to room temperature and the material was centrifuged, then washed repeatedly with absolute ethanol and dried in an oven at $100{ }^{\circ} \mathrm{C}$. Finally, the material was ground, sieved at 350 mesh and calcined at $550{ }^{\circ} \mathrm{C}$ for $4 \mathrm{~h}$, in a synthetic-air flow of $20 \mathrm{~mL} \mathrm{~min}^{-1}$ to obtain a white solid labelled ANW.

To promote the homogeneous dispersion of the Au nanoparticles onto the ANW surface, the support was modified with the coupling agent APTMS by methodologies reported by Dinamarca et al. [52]. In a two-necked, round-bottom flask, $100 \mathrm{~mL}$ of dry toluene, $5.0 \mathrm{~g}$ of ANW and $5 \mathrm{~mL}$ of APTMS were dispersed and stirred for $1 \mathrm{~h}$. The system was refluxed for a period of $24 \mathrm{~h}$ in inert atmosphere. The modified solid was centrifuged and washed with toluene $(1 \times 50 \mathrm{~mL})$ and ethanol $(2 \times 50 \mathrm{~mL})$ and dried in a vacuum oven for $12 \mathrm{~h}$ at $60^{\circ} \mathrm{C}$. The obtained solid was labelled as ANW-NH $\mathrm{NH}_{2}$.

Three catalysts were prepared at nominal Au loadings of 0.25, 0.50 and $1.0 \mathrm{wt} \%$. The synthesis was performed by dispersing $1.0 \mathrm{~g}$ of the $\mathrm{ANW}-\mathrm{NH}_{2}$ support in $10 \mathrm{~mL}$ of methanol. The solid was sonicated for $10 \mathrm{~min}$ and, subsequently, the necessary amount of solution, $5.16 \mathrm{mM} \mathrm{HAuCl}_{4}$ in methanol, was added to the dispersion, which was maintained under stirring for a period of $4 \mathrm{~h}$. Then, $2 \mathrm{~mL}$ of an aqueous solution of $0.1 \mathrm{M} \mathrm{NaBH}_{4}$ was added. Subsequently, the system was kept under stirring for a period of $30 \mathrm{~min}$. Finally, the dispersion was centrifuged and washed with water until it reached a neutral $\mathrm{pH}$. The catalysts were labelled as $(\mathrm{x}) \mathrm{Au} / \mathrm{ANW}$, where $\mathrm{x}$ corresponds to the nominal metal loading in the catalyst formulation.

\subsection{Characterization}

Chemical composition was probed by atomic absorption spectrometry (AAS) employing a Perkin Elmer 3100 instrument (Perkin Elmer, Manasquan, NJ, USA). The samples were evaluated in triplicate by microwave-assisted digestion of $0.05 \mathrm{~g}$ of the catalyst in $10 \mathrm{~mL}$ of concentrated $\mathrm{HNO}_{3} / \mathrm{HCl}$ 
dissolution (1:3, v/v). Solid-state ${ }^{13} \mathrm{C}$ and ${ }^{29} \mathrm{Si}$ cross-polarization (CP)-magic angle spinning (MAS) NMR spectra were recorded at 100.6 MHz and 79.49 MHz, respectively, using a Bruker AV $400 \mathrm{WB}$ spectrometer (Bruker, Rheinstetten Germany). Specific surface areas were calculated using the Brunauer-Emmett-Teller (BET) method from $\mathrm{N}_{2}$ adsorption-desorption isotherms, recorded at $-196^{\circ} \mathrm{C}$ using a Micromeritics TrisStarII 3020 instrument (Micromeritics, Norcross, GA, USA). X-ray powder diffraction (XRD) patterns were recorded using Ni-filtered $\mathrm{Cu} K_{\alpha 1}$ radiation $(\lambda=1.5418 \AA$ ) on a Rigaku diffractometer (Rigaku, Tokyo, Japan), in a $2 \theta$ range of $20-90^{\circ}$. Transmission electron microscopy (TEM) micrographs were obtained using a JEOL model JEM-1200 EX II microscope (JEOL, Tokyo, Japan). X-ray photoelectron spectra (XPS) were recorded using an Escalab $200 \mathrm{R}$ spectrometer (Thermo Scientific, Waltham, MA, USA) equipped with a hemispherical analyser and using non-monochromatic $\mathrm{Mg} \mathrm{K} \alpha$ $\mathrm{X}$-ray radiation $(\mathrm{h} v=1253.6 \mathrm{eV})$. The spectra were fitted to a combination of Gaussian-Lorentzian lines of variable proportion. The $\mathrm{C} 1 \mathrm{~s}$ core-level of adventitious carbon at a binding energy (BE) of $284.8 \mathrm{eV}$ was used as an internal standard.

\subsection{Catalytic Activity}

The catalytic activity of the Au-supported catalyst for the nitroarene hydrogenation was evaluated using $0.020 \mathrm{~g}$ catalyst samples and the amounts of substrate necessary to obtain a mol $\mathrm{substrate}_{\mathrm{pol}}: \mathrm{mol}_{\mathrm{Au}}$ ratio of 100, based on the metal contents determined by AAS. All activity measurements were performed in triplicate using a semi-batch $\operatorname{Parr}^{\circledR}$-type reactor with magnetic agitation filled with absolute ethanol as solvent $(50 \mathrm{~mL})$ at an $\mathrm{H}_{2}$ pressure of 20 bar and $75^{\circ} \mathrm{C}$. Products were identified by gas chromatography using a GC Hewlett Packard HP 4890 D gas chromatograph (Hewlett Packard HP-4890, Hewlett Packard, Palo Alto, CA, USA) equipped with an HP-5 capillary column and a flame-ionization detector. Conversion $\left(X_{\text {substrate }}\right)$ and selectivity $\left(S_{\text {product }}\right)$ were calculated based on calibration curves and the following equations:

$$
\begin{aligned}
& X_{\text {subtrate }}(\%)=\frac{\left([\text { substrate }]_{i}-[\text { substrate }]_{t}\right)}{[\text { substrate }]_{i}} \times 100 \\
& S_{\text {product }}(\%)=\frac{\left([\text { product }]_{t}\right)}{\left([\text { substrate }]_{i}-[\text { substrate }]_{t}\right)} \times 100
\end{aligned}
$$

where $\mathrm{i}$ corresponds to the concentration at the initial time $(t=0)$ and $\mathrm{t}$ is the concentration at any time different to the initial $(t>0)$.

To confirm the presence of byproducts, the reactions were monitored using a gas chromatograph coupled to a mass detector Perkin Elmer GCMS-SQ8T (Perkin Elmer, Manasquan, NJ, USA). For the solvent effect studies, the catalytic measurements were carried out employing the same reaction conditions, but the reactor was filled with acetonitrile, methanol, toluene, ethyl acetate or THF as solvents. Catalyst operational stability was probed by recycling tests. The catalyst was separated by hot filtration from its bed, washed three times with the reaction solvent and sequentially treated with $50 \mathrm{~mL}$ of fresh solvent and the amount of substrate required to repeat the reaction. This operation was repeated five times in succession.

\section{Results and Discussion}

\subsection{Support and Catalysts Characterization}

The incorporation of the APTMS functionality within the ANW support was confirmed by the solid-state NMR spectra. As shown in Figure 1a, the ${ }^{13} \mathrm{C}$ magic angle spinning (MAS) NMR spectra of the supports presented one group of typical signals at 13.3, 20.3 and $26.6 \mathrm{ppm}$, corresponding to $\mathrm{CH}_{2}$ groups from propyl-moiety, and signals detected at 50-60 ppm, which correspond to the $\mathrm{C}$ from $\mathrm{Si}-\mathrm{OCH}_{3}$ functional groups. In addition, the ${ }^{29} \mathrm{Si}$ cross-polarization (CP) MAS NMR spectra demonstrated the anchorage of APTMS on the ANW surface. As shown in Figure 1b, the NMR spectra of the $\mathrm{ANW}-\mathrm{NH}_{2}$ displayed typical signals distributed broadly from -45 to $-70 \mathrm{ppm}$, attributed to the 
presence of organic molecules with silyl ether groups. The typical isomer shift values in the literature for $\mathrm{T}^{1}, \mathrm{~T}^{2}$ and $\mathrm{T}^{3}$ signals at $-48.5,-58.5$ and $-67.5 \mathrm{ppm}$, respectively [53]. In our case, the main signals appears for the $\mathrm{T}^{2}-\mathrm{T}^{3}$ type of anchorage that is attributed to the grafting reaction between the surface $\mathrm{Al}-\mathrm{OH}$ groups and silane moieties to produce (Al-O) $)_{x}-\mathrm{Si}-\left(\mathrm{OCH}_{3}\right)_{3-\mathrm{x}}\left(\mathrm{CH}_{2} \mathrm{CH}_{2} \mathrm{CH}_{2}-\mathrm{NH}_{2}\right)$ with $\mathrm{x}=1$ and/or 2. This result is in line with the $\mathrm{C}$ signals detected at 50-60 ppm in NRM ${ }^{13} \mathrm{C}$ spectrum, which correspond to the unreacted methoxide-silyl ether groups.
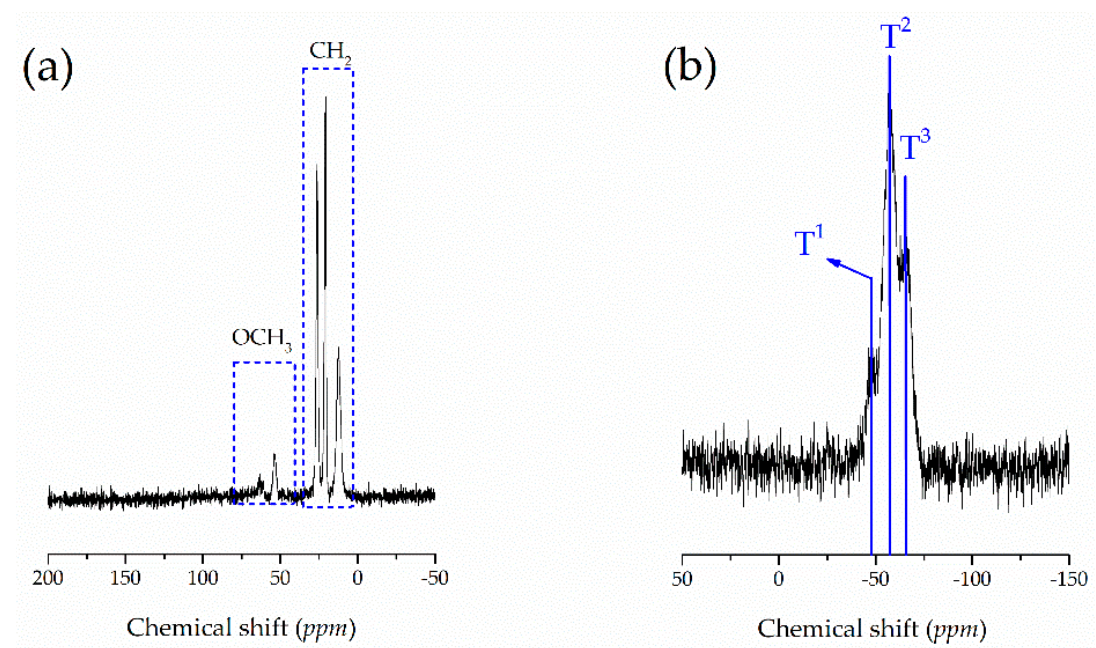

Figure 1. Solid state cross-polarization (CP)-magic angle spinning (MAS) $\mathrm{NMR}$ of the $\mathrm{Al}_{2} \mathrm{O}_{3}$ nanowires (ANW) modified with (3-Aminopropyl)trimethoxysilane (APTMS). (a) ${ }^{13} \mathrm{C}$ and (b) ${ }^{29} \mathrm{Si}$.

AAS characterization was carried out to quantify the Au content in the catalysts, as shown in Table 1 . The similarity of experimental and nominal metal contents indicated the absence of appreciable metal loss during synthesis of the catalysts.

Table 1. Physicochemical characterization data obtained by atomic absorption spectrometry (AAS), $\mathrm{N}_{2}$ isotherms and transmission electron microscopy (TEM) for the pristine ANW support, $\mathrm{ANW}-\mathrm{NH}_{2}$ and xAu/ANW catalysts.

\begin{tabular}{ccccc}
\hline Material & Au Loading (\%) & $\left.\mathbf{S}_{\text {BET }} \mathbf{( m}^{\mathbf{2}} \mathbf{g}^{-\mathbf{1}}\right)$ & ANW d $\mathbf{d}_{\text {pore }}(\mathbf{n m})$ & Au d $\mathbf{d}_{\text {TEM }}(\mathbf{n m})$ \\
\hline ANW & - & 204 & 8.9 & - \\
$\mathrm{ANW}-\mathrm{NH}_{2}$ & - & 154 & 8.5 & - \\
$0.25 \mathrm{Au} / \mathrm{ANW}$ & 0.21 & 138 & 8.0 & $3.7 \pm 1.8$ \\
$0.50 \mathrm{Au} / \mathrm{ANW}$ & 0.42 & 126 & 8.1 & $4.0 \pm 1.1$ \\
$1.00 \mathrm{Au} / \mathrm{ANW}$ & 0.87 & 115 & 7.9 & $4.6 \pm 2.6$ \\
\hline
\end{tabular}

Figure 2 displays the adsorption-desorption isotherms of $\mathrm{N}_{2}$ at $-196{ }^{\circ} \mathrm{C}$ for the as-synthetized materials. The analysis of isotherms and $\mathrm{S}_{\mathrm{BET}}$ (Table 1) shows that all the solids were mesoporous and had a type IV, according with to IUPAC classification, and possess hysteresis cycle type H1, corresponding to cylindrical pores. Moreover, all of them displayed monomodal mesopore-size distributions. This information allows us to infer that, as the Au loading increased on the supports, the values of surface area, pore volume, and pore size dropped, due to the anchoring of APTMS and the metallic nanoparticles on the surface, respectively.

The characterization by XRD of the supports and catalysts prepared is shown in Supplementary Material (Figure S1). In all cases, the typical diffractions for $\gamma-\mathrm{Al}_{2} \mathrm{O}_{3}$ (JCPDS 86-1410) were detected. The solid maintains the diffraction pattern for the support after the APTMS immobilization treatment. Differences attributed to metallic $\mathrm{Au}$ are not detected, as the diffractions for $\mathrm{Au}(111)$ at $2 \theta=38.1^{\circ}$ and (200) at $2 \theta=45.0^{\circ}$ are masked by the diffractions of the ANW support. 


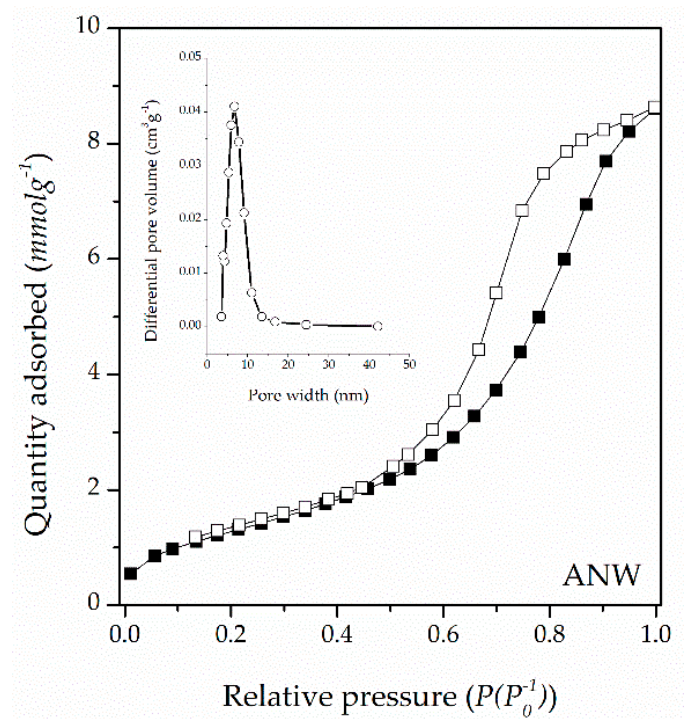

(a)

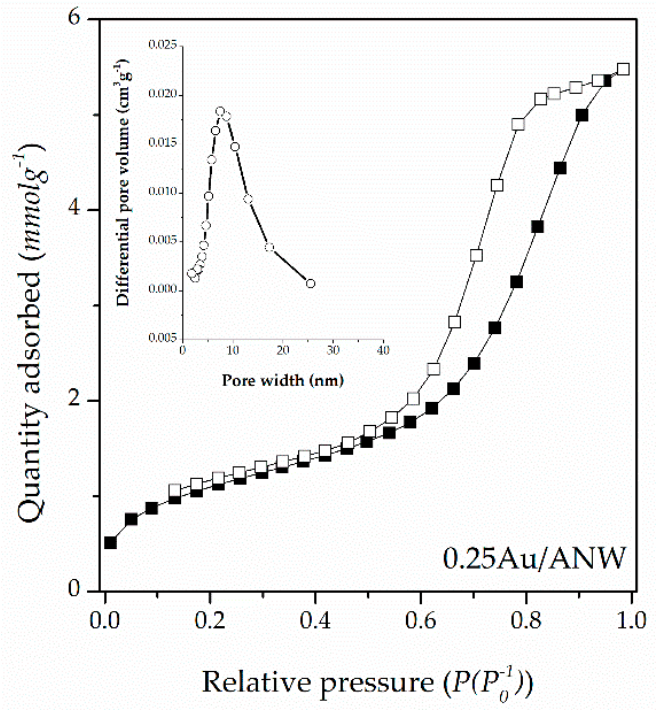

(c)

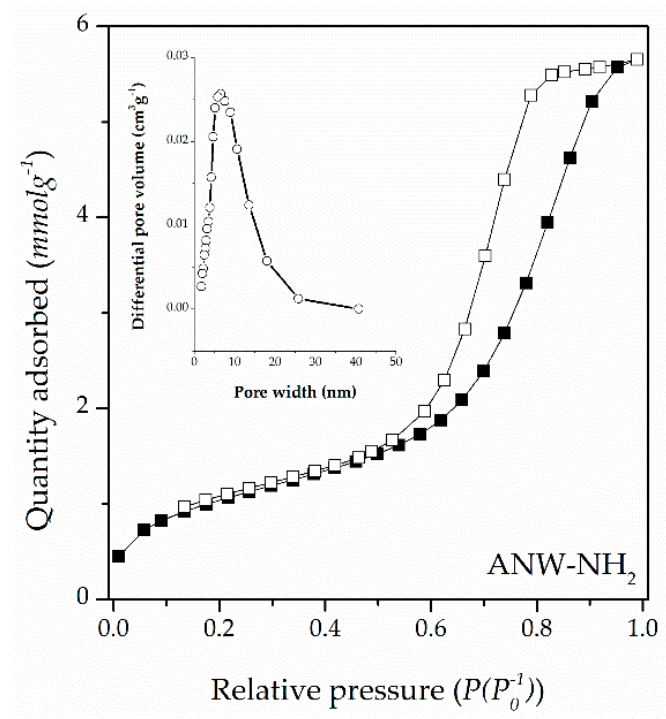

(b)

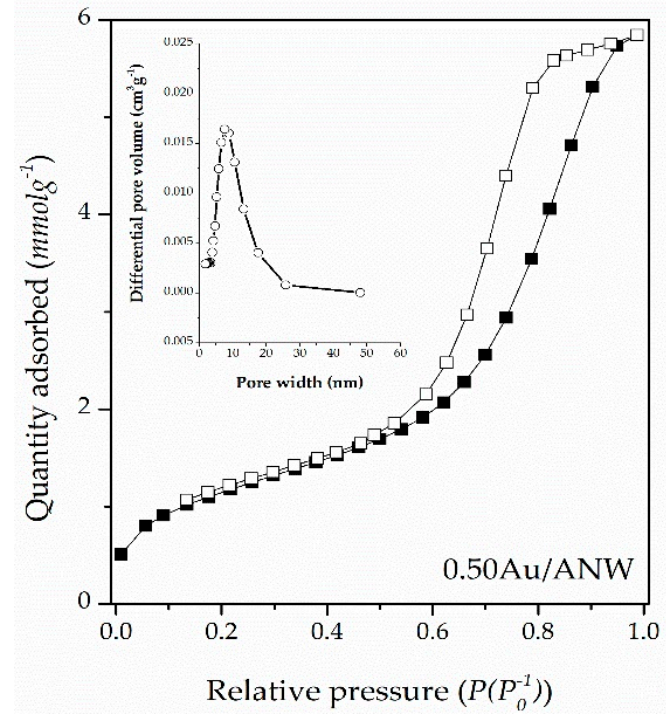

(d)

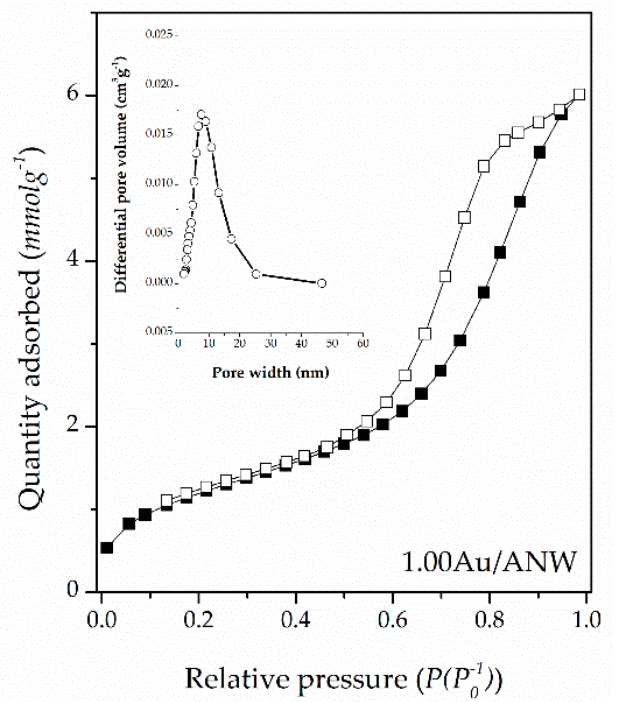

(e)

Figure 2. $\mathrm{N}_{2}$ adsorption-desorption isotherms and pore-size distribution curves of the prepared materials. (a) ANW; (b) ANW-NH ; $_{\text {(c) }} 0.25 \mathrm{Au} / \mathrm{ANW}$; (d) $0.50 \mathrm{Au} / \mathrm{ANW}$; (e) 1.00Au/ANW. Close square corresponds to adsorption branch and open square corresponds to the desorption branch. 
The micrographs of TEM for ANW, ANW- $\mathrm{NH}_{2}$ and the catalysts (x)Au/ANW are shown in Figure 3. The morphology of pristine and modified nanowires is confirmed and no change in morphology is observed after metal deposition. ANW support was modified on its surface with APTMS to promote the uniform deposition of metal nanoparticles once they are deposited in the material. According with our previous reported results, the use of APTMS enhanced the uniform distribution of the metal precursor on the nanomaterials surface [52]. This behaviour is attributed to a ligand exchange between chlorine $\left(\mathrm{Cl}^{-}\right)$groups of $\mathrm{AuCl}_{4}{ }^{-}$metal precursor and amine $\left(\mathrm{NH}_{2}\right)$ groups from the immobilized APTMS. The $\mathrm{HAuCl}_{4}$ can exchange the chloride ligand with $\mathrm{NH}_{2}$, providing the formation of mixed amine-chloro complexes $\left[\mathrm{AuCl}_{4-\mathrm{x}}\left(\mathrm{NH}_{2}\right)_{\mathrm{x}}\right]^{\mathrm{x}-1}$, as has been reported by Lei et al. [54]. According with TEM characterization, all the $(x) \mathrm{Au} / \mathrm{ANW}$ catalysts showed Au nanoparticles with narrow particle size distributions. The average size of the nanoparticles increases as the metallic content of $\mathrm{Au}$ in the catalysts increases, as shown in Table 1. We suggest that the increase in the metal loading promotes the Au NPs' agglomeration following the Ostwald ripening process during the reduction process with $\mathrm{NaBH}_{4}$.

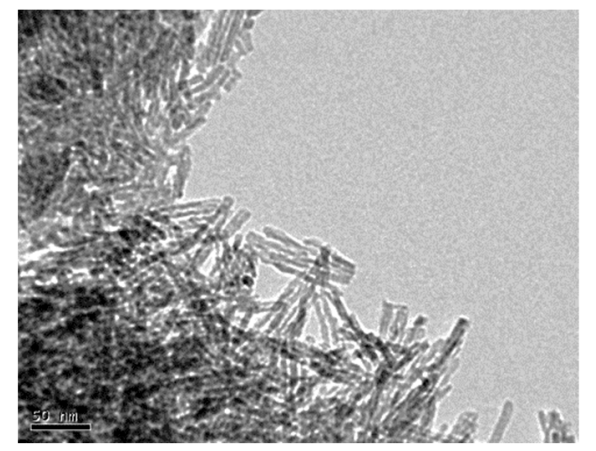

(a)
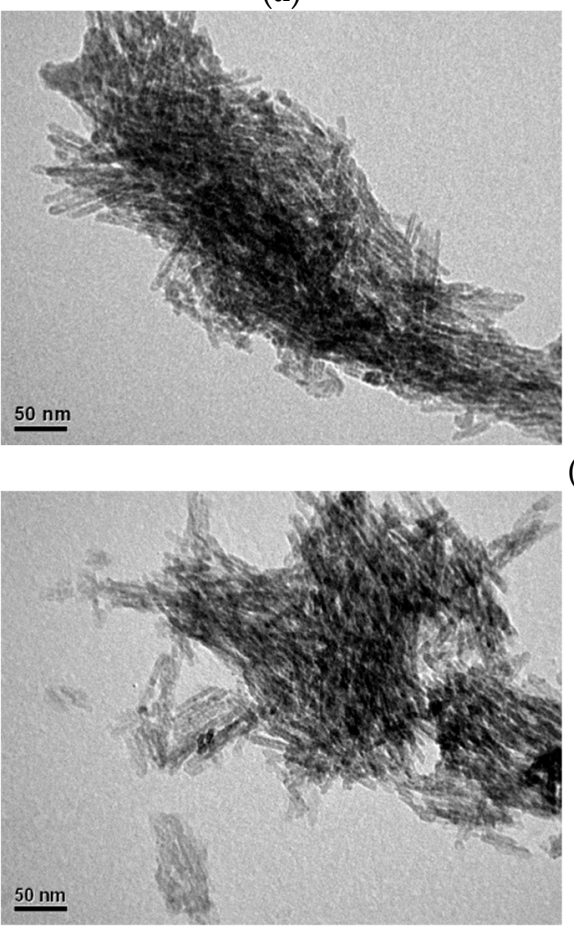

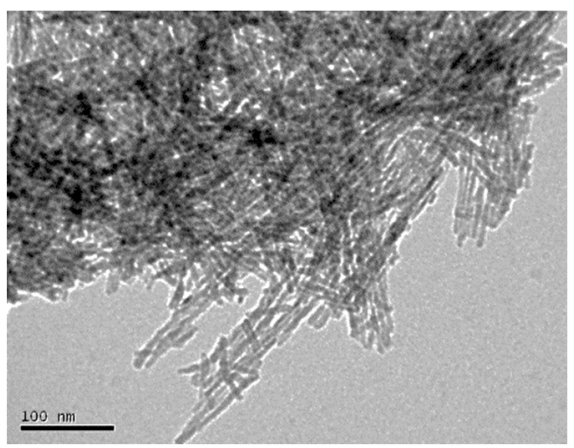

(b)

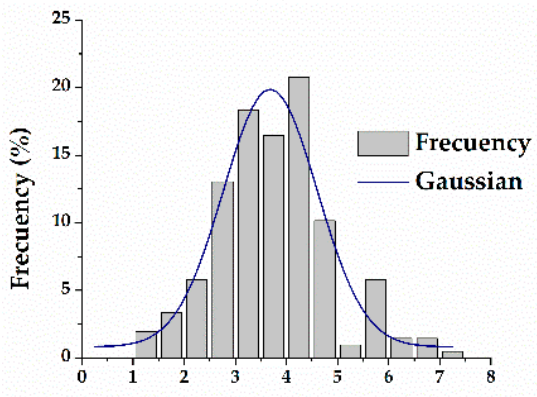

$\mathrm{Au}$ particle diameter $(\mathrm{nm})$

(c)

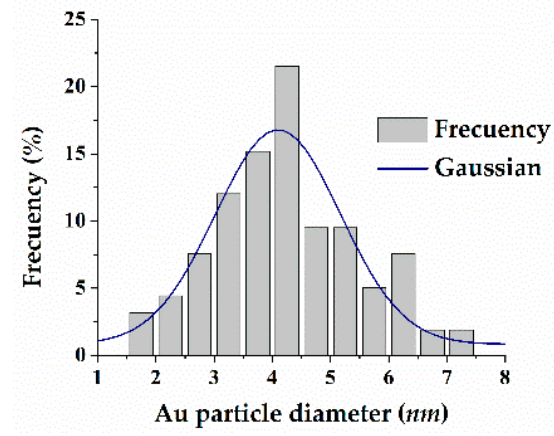

(d)

Figure 3. Cont. 

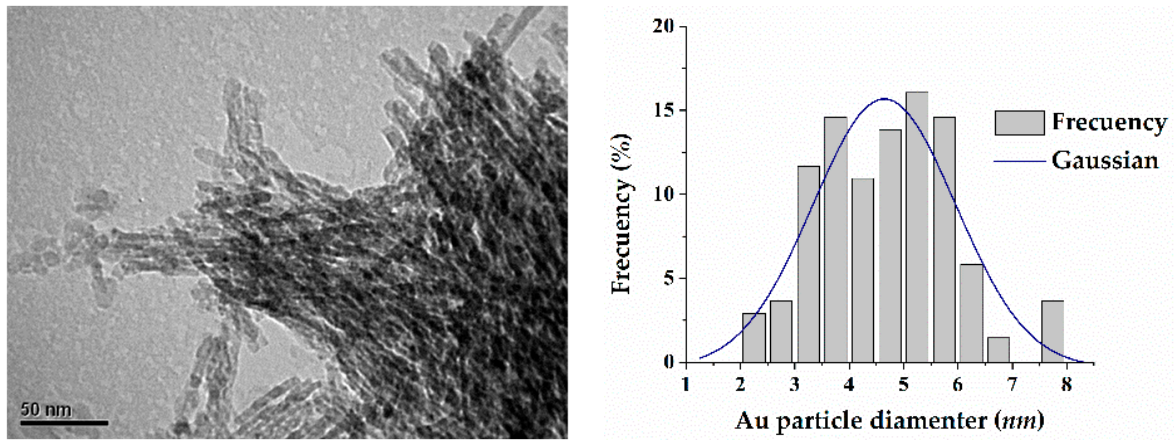

(e)

Figure 3. TEM micrographs and Au NPs size distribution of the as-synthesized supports and catalysts.

(a) ANW; (b) ANW-NH ${ }_{2}$; (c) $0.25 \mathrm{Au} / \mathrm{ANW}$; (d) $0.50 \mathrm{Au} / \mathrm{ANW}$ and (e) $1.00 \mathrm{Au} / \mathrm{ANW}$.

Figure 4 show the characterization of the catalysts by UV-vis-NIR diffuse reflectance spectroscopy (DRS). Pristine ANW did not show any contribution absorbance band in the visible wavelength range. All the catalytic systems showed a broad surface plasmon resonance (SPR) adsorption peak centred at $524 \mathrm{~nm}$ [55]. In addition, all the catalytic system showed a second absorption band at 250-260 nm which is characteristic of cationic gold species [56,57]. An increase in the contribution of cationic Au species with the increase of Au loading was observed. This trend could be attributed to the incomplete reduction of metal-precursor during the treatment with $\mathrm{NaBH}_{4}$. According with $\mathrm{N}_{2}$ isotherms and TEM characterization, the increase of Au metal particles size with the increase of metal loading produced a pores blockage; this occlusion could be inhibit the reduction of the sorbed $\left[\mathrm{AuCl}_{4-\mathrm{x}}\left(\mathrm{NH}_{2}\right)_{\mathrm{x}}\right]^{\mathrm{x}-1}$ species into the pores structures.

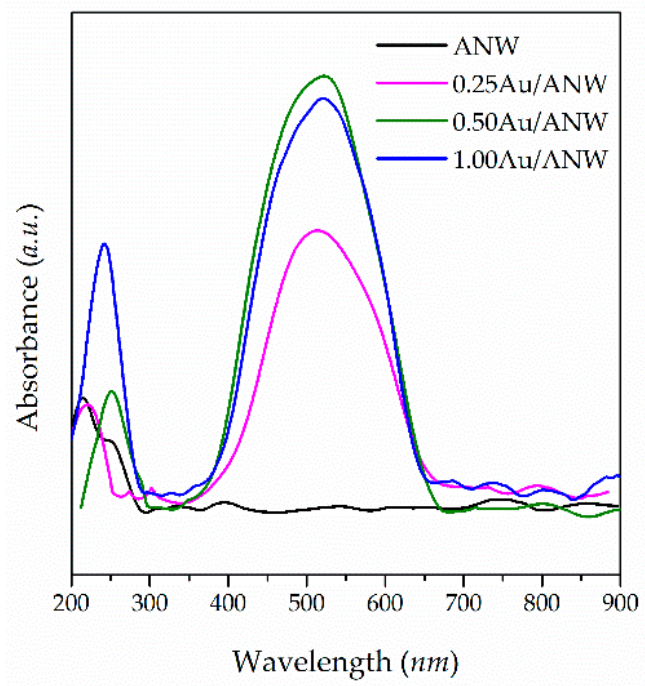

Figure 4. UV-vis-NIR diffuse reflectance spectroscopy (DRS) of ANW support and (x)Au/ANW catalysts.

To confirm surface electronic states and the chemical composition of the prepared system, all the catalysts were examined by using X-ray photoelectron characterization (XPS), as shown in Figure 5. The binding energies (BE) of the $\mathrm{Au} 4 \mathrm{f}_{7 / 2}$ states for $\mathrm{Au} / \mathrm{ANW}$ catalysts are located at $83.5-83.9 \mathrm{eV}$ (see Table 2), which agree with the values reported in the literature for metallic $A u[12,13,18]$. In addition, some cationic species with $\mathrm{Au} 4 \mathrm{f}_{7 / 2}$ signals located at 84.5-85.1 eV [58], respectively, are also detected. 

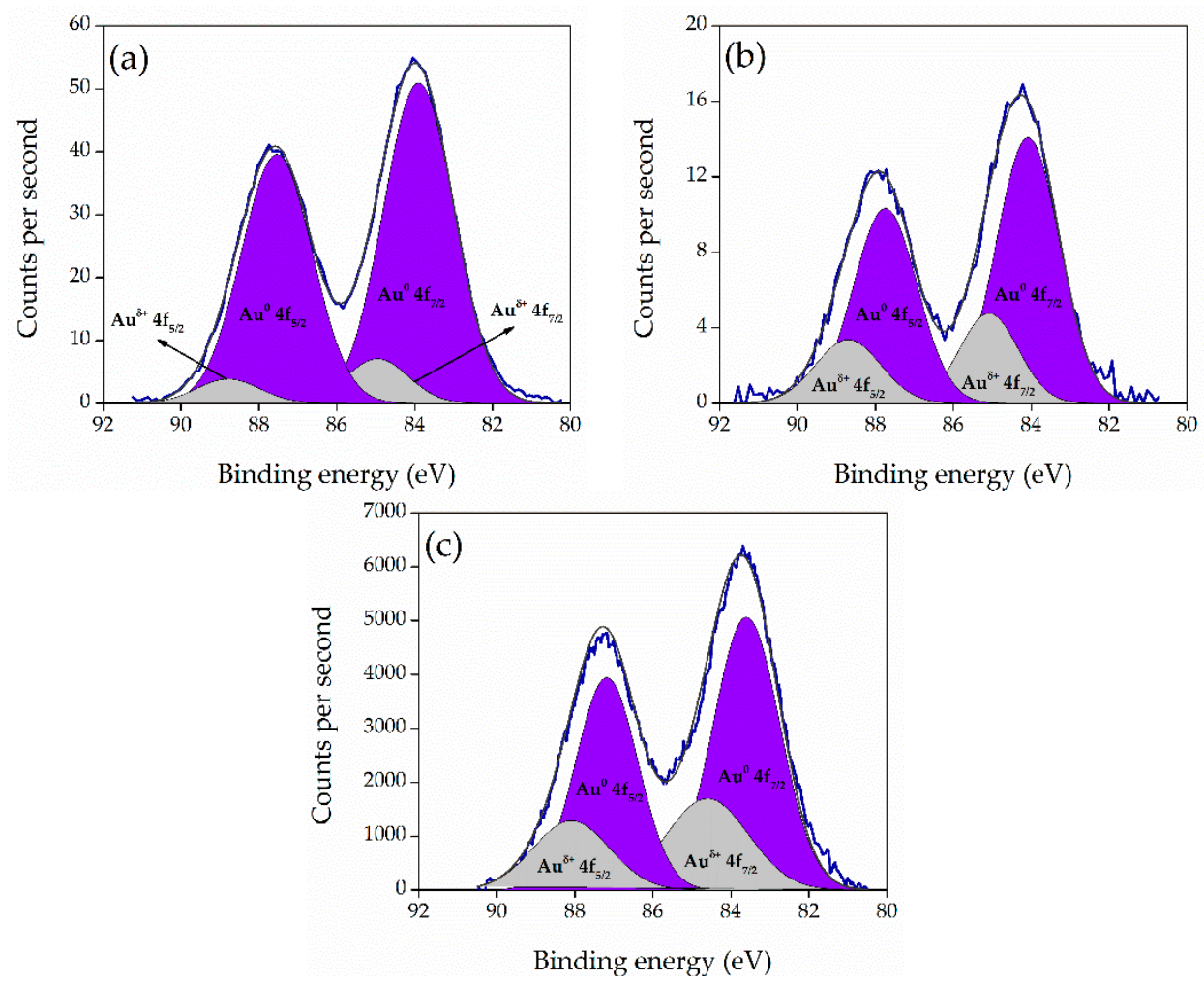

Figure 5. X-ray photoelectron spectra (XPS) spectra of Au $4 \mathrm{f}$ for the as-synthetized (x)Au/ANW catalysts. (a) $\mathrm{x}=0.25 ;$ (b) $\mathrm{x}=0.50$ and $(\mathbf{c}) \mathrm{x}=1.00$.

Table 2. Binding energies (BE) of internal levels and atomic ratio of (x)Au/ANW catalysts. (Percentage in brackets).

\begin{tabular}{|c|c|c|c|c|c|}
\hline \multirow{2}{*}{$\mathbf{x}$} & \multirow{2}{*}{ Al 2p (eV) } & \multicolumn{2}{|c|}{$\mathrm{Au} 4 \mathrm{f}_{7 / 2}(\mathrm{eV})$} & \multirow{2}{*}{ O 1s (eV) } & \multirow{2}{*}{$\mathrm{Au} / \mathrm{Al}$ at } \\
\hline & & $\mathbf{A u} \mathbf{u}^{0}$ & $A \mathbf{u}^{\delta+}$ & & \\
\hline 0.25 & 74.5 & $83.6(91)$ & $84.8(9)$ & 531.4 & 0.022 \\
\hline 0.50 & 74.5 & $83.8(84)$ & $85.0(16)$ & 531.3 & 0.031 \\
\hline 1.00 & 74.4 & $84.0(78)$ & $85.1(22)$ & 531.3 & 0.009 \\
\hline
\end{tabular}

This behaviour is agreement with the DRS UV-Vis characterization results. The presence of $\mathrm{Au}^{\delta+}$ species after reduction treatment was attributed to an incomplete reduction of the metal-precursor during the catalyst synthesis. Moreover, it should be noted that, as the Au content decreases, $\mathrm{Au} 4 \mathrm{f}_{7 / 2}$ BE shifted from $83.9 \mathrm{eV}$ for 1.00Au/ANW catalyst, to $83.4 \mathrm{eV}$, in the case of $0.25 \mathrm{Au} / \mathrm{ANW}$. This kind of shift in $\mathrm{BE}$ is very common for very small gold particles supported in $\mathrm{Al}_{2} \mathrm{O}_{3}$ supports, due to reduced core-hole screening in small metal particles [44]. This indicates that there are significant differences in the electronic properties of very small particles and bulk materials and that the dimensionally dependent changes in the electronic structure produce unusual characteristics $[40,59,60]$.

\subsection{Catalytic Activity}

\subsubsection{Effect of Au Loading}

The catalytic activities of the (x)Au/ANW catalysts are shown in Figure 6. The kinetics measurements revealed that the supported Au catalysts exhibited a high efficiency in both the NFMF and the NFMO hydrogenation reactions, showing a pseudo-first order kinetics, with respect to the substrate consume. During the reaction course, the formation of the corresponding anilines ( $>99 \%)$ 
was highly favoured over the accumulation of reaction intermediates (Scheme 3), showing that the (x)Au/ANW systems are very selective catalysts for nitroarenes hydrogenation.
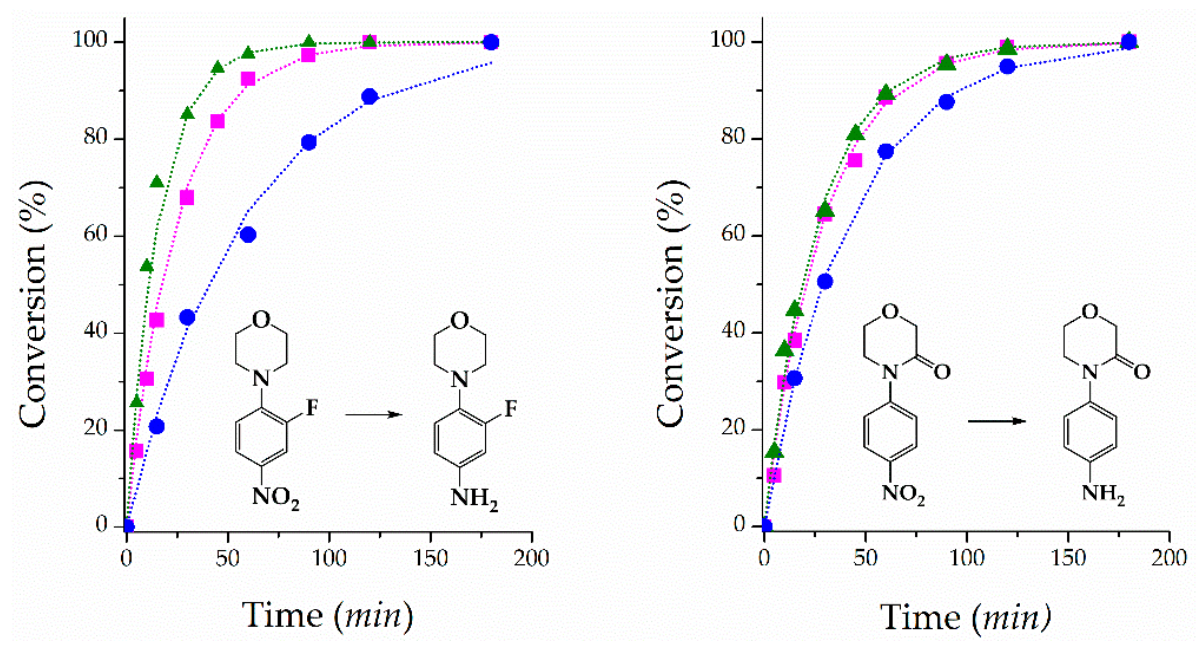

Figure 6. Conversion curves as a function of time for hydrogenation of the substrates of pharmaceutical interest on the catalysts (x)Au/ANW. - $-0.25 \mathrm{Au} / \mathrm{ANW} ; \mathbf{\Delta}-0.50 \mathrm{Au} / \mathrm{ANW}$ and $\bullet-1.00 \mathrm{Au} / \mathrm{ANW}$. Straight lines correspond to the kinetic pseudo-first order adjustment.

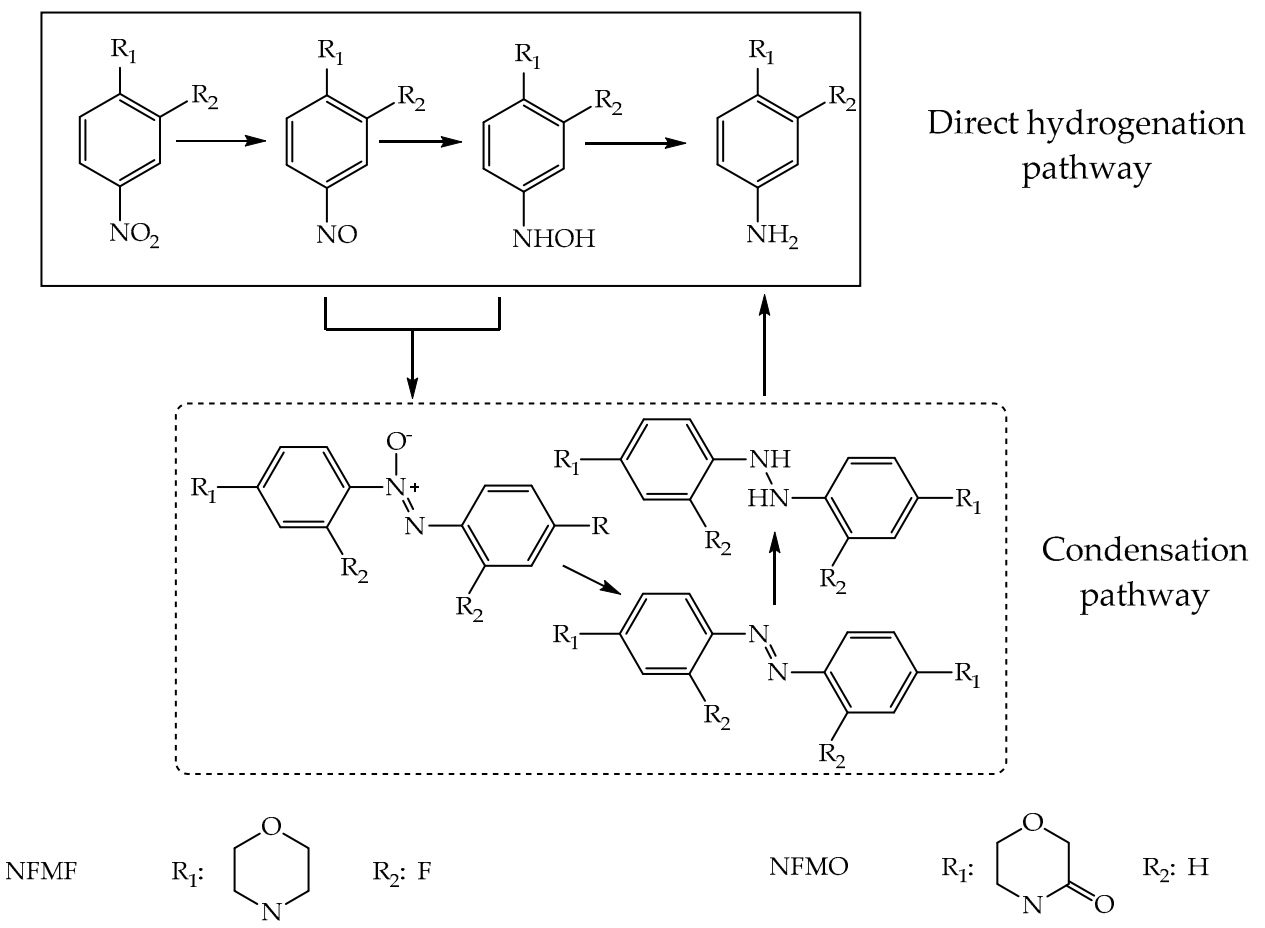

Scheme 3. Reaction pathways for nitroarenes' hydrogenation.

These findings are in agreement with the experimental conclusions reported by Torres et al. on a $\mathrm{TiO}_{2}$ nanotubes-supported gold catalyst [18]. A relevant outcome regarding these results is that high catalytic activity and high selectivity towards hydrogenation to anilines were achieved by the (x)Au/ANW systems, despite their low metal content. In this context, our catalyst shows better performance than previous reports from Gardiner et al. that used Pd immobilized to hydrogenated NFMF reaching to $30 \%$ of yield to the amine-arene desire [46]. With respect to selectivity, one intermediate reaction was detected, namely $\mathrm{N}$-(substituted-phenyl)-hydroxylamine derivate $(<1 \%)$, with no evidence of condensation byproducts. Both intermediates were detected at very low 
concentrations, thus supporting the predominance of a direct hydrogenation route over a condensation route, as shown in Scheme 3. To confirm our results, two control experiments were performed: catalytic reaction in the absence of hydrogen to rule out the reduction of both nitroarenes by hydrogen transfer using ethanol as $\mathrm{H}$ donor and the reaction in the absence of the catalyst. In all experiments, no conversions greater than $5 \%$ were detected at $24 \mathrm{~h}$ of operation.

Regarding the effect of the metallic charge, a direct dependence of the reaction rate is observed as a function of the metal loading. In the case of 1.00Au/ANW catalyst showed the largest particle size and the lowest conversion compared to the systems with lower metal content. The decrease of catalytic performance could be attributed to the Au metal mean particle size. The presence of Au nanoparticles with $\mathrm{d}_{\mathrm{TEM}}=4.6 \pm 2.6 \mathrm{~nm}$ on the $1.00 \mathrm{Au} / \mathrm{ANW}$ catalyst surface often results in reduced activity of the catalyst due to diffusion limitations and/or blocking of active sites. In the case of $0.25 \mathrm{Au} / \mathrm{ANW}$ and $0.50 \mathrm{Au} / \mathrm{ANW}$, both catalysts have a similar particle size, the 0.25Au/ANW catalyst has less $\mathrm{Au}$ availability on the surface compared to 0.50Au/ANV, as shown in the characterization by XPS, as shown in Table 2.

\subsubsection{Effect of the Solvent}

The best activity results were shown by the catalyst 0.50Au/ANW, in which different solvents were evaluated. The selected solvents were ethanol, methanol, water, THF, acetonitrile and ethyl acetate, as shown in Figure 7. It is observed that, in the case of aprotic-polar solvents, the conversion of the substrates and the selectivity of the product decreases compared to the protic solvents. The accumulation of $\mathrm{N}$-(substituted-phenyl)-hydroxylamine intermediaries were detected reaching selectivities of $\sim 5 \%$ for both NFMF and NFMO substrates when THF was used as solvent. However, in the case of protic solvents, higher reaction rates and a very low accumulation of reaction intermediates $(<1 \%)$ are detected.
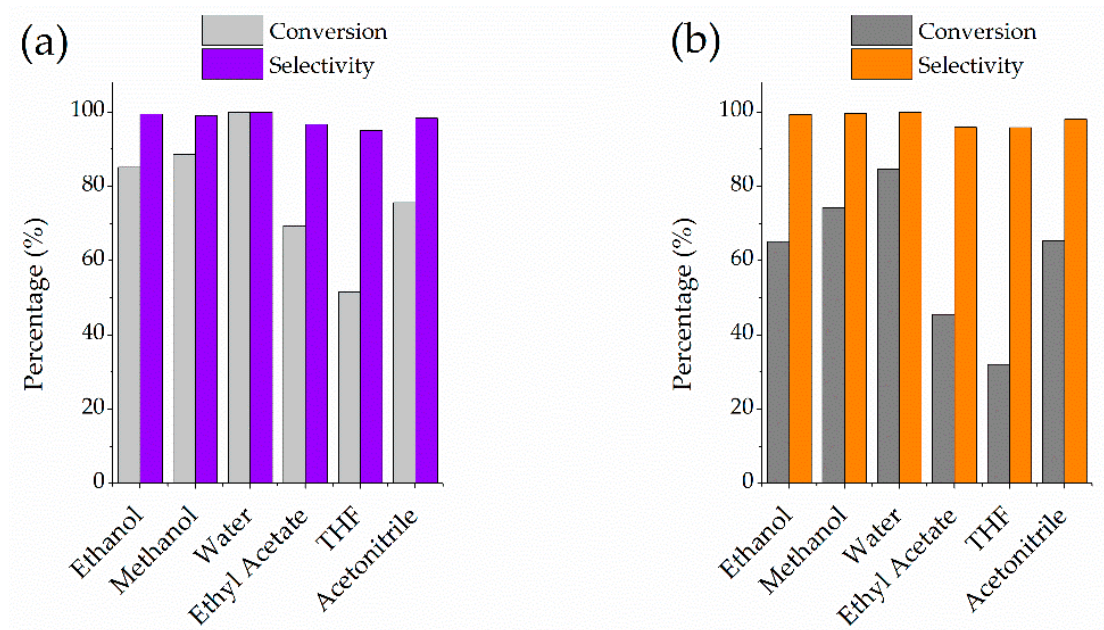

Figure 7. Effect of the solvent on the activity and selectivity in the hydrogenation of the selected nitroarenes at $30 \mathrm{~min}$ of reaction. (a) 4-(2-fluoro-4-nitrophenyl)-morpholine (NFMF) and (b) 4-(4-nitrophenyl)3-morpholinone (NFMO).

These results suggest that the protic solvents favour both activity and selectivity in the hydrogenation reaction, whereas aprotic-polar solvents showed an opposite trend. This behaviour could be explained considering the proposed Haber reaction mechanism, in which the rate-limiting step involves the hydrogenation of N-phenyl-hydroxylamine derivate to the corresponding aniline, as shown in Scheme 3. A growing electron density on the $\mathrm{N}$ atom is expected to occur in the transition state of this rate-determining step [61]. We suggest the presence of protic solvents can stabilize the transition state, thus accelerating the hydrogenation of $\mathrm{N}$-(substituted-phenyl)-hydroxylamine intermediaries, to produce the corresponding anilines in comparison with aprotic-polar solvents. 
Although complete conversion and selectivity ( $>99 \%)$ was obtained in the presence of water as a reaction medium for the hydrogenation of both NFMF and NFMO, the conversion followed the order ethanol $<$ methanol $<$ water. However, despite the solvent, the corresponding anilines selectivity ranged between $98 \%$ and $99.5 \%$. The use of water as a solvent in reaction was found to be most effective in the hydrogenation of these nitroarenes compared to the other solvents.

\subsubsection{Reusability and Operational Stability of the Catalyst}

In order to assess both reuse capacity and the operational stability of the $0.5 \mathrm{Au} / \mathrm{ANW}$ catalyst, water and ethanol were chosen as solvents, as shown in Figure 8. It is observed that the catalyst shows different operational stability depending on the solvent used. In the case of water, a continuous loss of conversion is detected, reaching a maximum conversion around $70 \%$ at the third operating cycle in both substrates evaluated. For the use of ethanol, it can be observed that it reaches higher operational stability, reaching $80 \%$ conversion in the fifth operating cycle. After each operation cycle, AAS characterization of the supernatant was performed to evaluate the metal leachate between operation cycles.
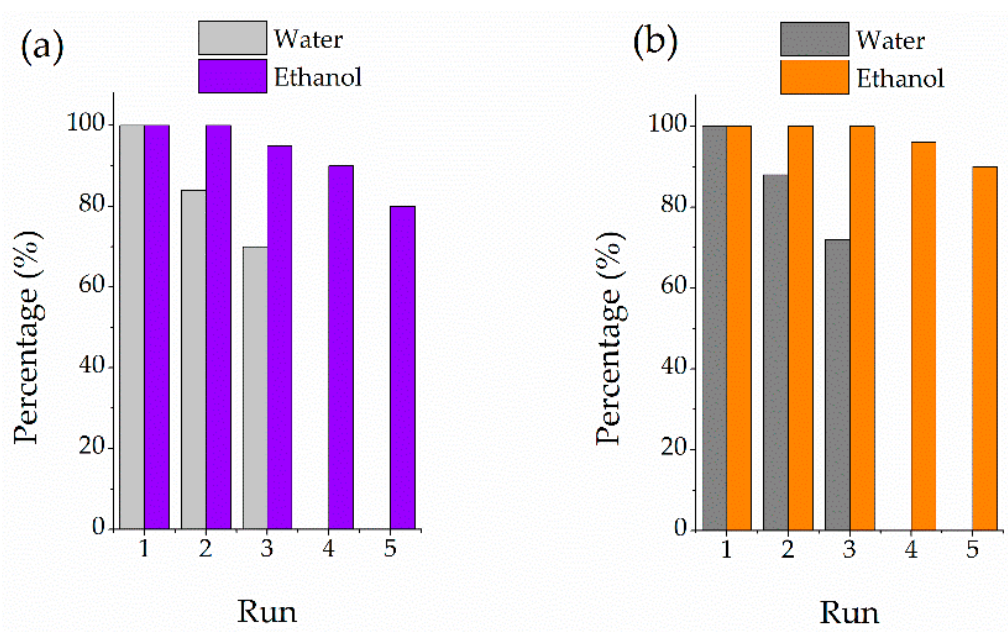

Figure 8. Recycling studies in the hydrogenation of (a) NFMF and (b) NFMO at 180 min of reaction using water and ethanol as solvent.

In the case of the use of water recycling, a leaching of about $46 \%$ of the metal was detected at the end of the three operating cycles as shown in Table S1 in the Supplementary Material. Under the operating conditions, in an aqueous medium, hydrothermal reactions on the catalyst surface that promote the leaching of the active phase to the reaction medium are favoured [62-64]. However, when ethanol is used as a solvent, only about $8 \%$ metal leaching was detected after the fifth operating cycle. These results correlate directly with the stability shown by the support in aqueous medium.

\section{Conclusions}

It was possible to synthesize heterogeneous catalysts based on Au nanoparticles supported in $\mathrm{Al}_{2} \mathrm{O}_{3}$ nanowires that were active, selective and with moderate operational stability, in the hydrogenation of nitroarenes of pharmaceutical interest. The catalytic properties were controlled with the metal loading on the supports where it was found that, with a nominal content of $0.50 \%$ mass of Au, an optimal system for the reaction of interest was obtained. The effect of the solvent plays an important role in the activity and selectivity of the catalyst, where the highest efficiency and operational stability was achieved when ethanol is used as the solvent. Five consecutive cycles were achieved using ethanol, reaching $80 \%$ conversion in the last run for the best catalytic systems.

Supplementary Materials: The following are available online at http://www.mdpi.com/1996-1944/13/4/925/s1. 
Author Contributions: K.S. performed the synthesis of the catalysts and TEM characterization; T.M.B. performed the organic molecules synthesis and catalytic measurements. C.H.C. performed the design of the organic molecules synthesis and catalytic result analysis, review and edits the manuscript; C.C.T. performed the XRD, DRS-UV Vis and $\mathrm{S}_{\mathrm{BET}}$ characterizations, and catalytic result analysis and wrote the manuscript. All authors have read and agreed to the published version of the manuscript.

Funding: This research was funded by CONICYT project FONDECYT 1191465 and FONDECYT 3180232.

Acknowledgments: T.M.B. thanks to CONICYT Grant 21190739. We thank to J.L.G. Fierro, Instituto de Catálisis y Petroleoquímica in Madrid-Spain, for XPS measurement. C.C.T. thanks to CONICYT, PAI/Concurso Nacional Inserción de Capital Humano Avanzado en la Academia Convocatoria año 2017 PAI79170027.

Conflicts of Interest: The authors declare no conflict of interest.

\section{References}

1. Ferretti, F.; Ramadan, D.R.; Ragaini, F. Transition Metal Catalyzed Reductive Cyclization Reactions of Nitroarenes and Nitroalkenes. ChemCatChem 2019, 11, 4450-4488. [CrossRef]

2. Song, J.; Huang, Z.-F.; Pan, L.; Li, K.; Zhang, X.; Wang, L.; Zou, J.-J. Review on selective hydrogenation of nitroarene by catalytic, photocatalytic and electrocatalytic reactions. Appl. Catal. B Environ. 2018, 227, 386-408. [CrossRef]

3. Ley, S.V.; Baxendale, I.R. New tools and concepts for modern organic synthesis. Nat. Rev. Drug Discov. 2002, 1, 573-586. [CrossRef] [PubMed]

4. Vennerstrom, J.L. Book Review of the Art of Drug Synthesis. J. Med. Chem. 2008, 51, 1502. [CrossRef]

5. Romanazzi, G.; Fiore, A.M.; Mali, M.; Rizzuti, A.; Leonelli, C.; Nacci, A.; Mastrorilli, P.; Dell'Anna, M.M. Polymer supported Nickel nanoparticles as recyclable catalyst for the reduction of nitroarenes to anilines in aqueous medium. Mol. Catal. 2018, 446, 31-38. [CrossRef]

6. Kadam, H.K.; Tilve, S.G. Advancement in methodologies for reduction of nitroarenes. RSC Adv. 2015, 5, 83391-83407. [CrossRef]

7. Patil, Y.S.R.D. Chemoselective Reduction of Nitroarenes to Aromatic Amines with Commercial Metallic Iron Powder in Water under Mild Reaction Conditions. Org. Chem. Curr. Res. 2015, 4, 1-4. [CrossRef]

8. Shimizu, K.-I.; Miyamoto, Y.; Kawasaki, T.; Tanji, T.; Tai, Y.; Satsuma, A. Chemoselective Hydrogenation of Nitroaromatics by Supported Gold Catalysts: Mechanistic Reasons of Size- and Support-Dependent Activity and Selectivity. J. Phys. Chem. C 2009, 113, 17803-17810. [CrossRef]

9. Tamura, M.; Yuasa, N.; Nakagawa, Y.; Tomishige, K. Selective hydrogenation of nitroarenes to aminoarenes using a MoOx-modified $\mathrm{Ru} / \mathrm{SiO}_{2}$ catalyst under mild conditions. Chem. Commun. 2017, 53, 3377-3380. [CrossRef]

10. Tian, H.; Zhou, J.; Li, Y.; Wang, Y.; Liu, L.; Ai, Y.; Hu, Z.-N.; Li, J.; Guo, R.; Liu, Z.; et al. Rh Catalyzed Selective Hydrogenation of Nitroarenes under Mild Conditions: Understanding the Functional Groups Attached to the Nanoparticles. Chem CatChem 2019, 11, 5543-5552. [CrossRef]

11. Corma, A. Chemoselective Hydrogenation of Nitro Compounds with Supported Gold Catalysts. Science 2006, 313, 332-334. [CrossRef] [PubMed]

12. Torres, C.; Campos, C.; Fierro, J.L.G.; Oportus, M.; Reyes, P. Nitrobenzene Hydrogenation on $\mathrm{Au} / \mathrm{TiO} 2$ and $\mathrm{Au} / \mathrm{SiO} 2$ Catalyst: Synthesis, Characterization and Catalytic Activity. Catal. Lett. 2013, 143, 763-771. [CrossRef]

13. Campos, C.; Jofre, M.; Torres, C.; Pawelec, B.; Fierro, J.; Reyes, P. Chemoselective hydrogenation of o-, p- and m-chloronitrobenzene at ambient temperature on $\mathrm{Au} / \mathrm{Fe}_{2} \mathrm{O}_{3}$ catalysts. Appl. Catal. A Gen. 2014, 482, 127-136. [CrossRef]

14. Wang, X.; Cárdenas-Lizana, F.; Keane, M.A. Toward Sustainable Chemoselective Nitroarene Hydrogenation Using Supported Gold as Catalyst. ACS Sustain. Chem. Eng. 2014, 2, 2781-2789. [CrossRef]

15. Serna, P.; Corma, A. Transforming Nano Metal Nonselective Particulates into Chemoselective Catalysts for Hydrogenation of Substituted Nitrobenzenes. ACS Catal. 2015, 5, 7114-7121. [CrossRef]

16. Torres, C.C.; Alderete, J.B.; Pecchi, G.; Campos, C.H.; Reyes, P.; Pawelec, B.; Vaschetto, E.G.; Eimer, G.A. Heterogeneous hydrogenation of nitroaromatic compounds on gold catalysts: Influence of titanium substitution in MCM-41 mesoporous supports. Appl. Catal. A Gen. 2016, 517, 110-119. [CrossRef] 
17. Wang, L.; Zhang, J.; Wang, H.; Shao, Y.; Liu, X.; Wang, Y.-Q.; Lewis, J.P.; Xiao, F.-S. Activity and Selectivity in Nitroarene Hydrogenation over Au Nanoparticles on the Edge/Corner of Anatase. ACS Catal. 2016, 6, 4110-4116. [CrossRef]

18. Torres, C.C.; Jiménez, V.A.; Campos, C.H.; Alderete, J.B.; Dinamarca, R.; Bustamente, T.M.; Pawelec, B. Gold catalysts supported on $\mathrm{TiO}_{2}$-nanotubes for the selective hydrogenation of p-substituted nitrobenzenes. Mol. Catal. 2018, 447, 21-27. [CrossRef]

19. Begum, R.; Rehan, R.; Farooqi, Z.H.; Butt, Z.; Ashraf, S. Physical chemistry of catalytic reduction of nitroarenes using various nanocatalytic systems: Past, present, and future. J. Nanopartic. Res. 2016, 18, 231. [CrossRef]

20. Perez-Lloret, M.; Fraix, A.; Petralia, S.; Conoci, S.; Tafani, V.; Cutrone, G.; Vargas-Berenguel, A.; Gref, R.; Sortino, S. One-Step Photochemical Green Synthesis of Water-Dispersible Ag, Au, and Au@Ag Core-Shell Nanoparticles. Chem. A Eur. J. 2019, 25, 14638-14643. [CrossRef]

21. Shin, H.-S.; Huh, S. Au/Au@Polythiophene Core/Shell Nanospheres for Heterogeneous Catalysis of Nitroarenes. ACS Appl. Mater. Interf. 2012, 4, 6324-6331. [CrossRef] [PubMed]

22. Pan, X.; Zheng, J.; Zhang, L.; Yi, Z. Core-Shell Au@SnO 2 Nanostructures Supported on Na2Ti4O9 Nanobelts as a Highly Active and Deactivation-Resistant Catalyst toward Selective Nitroaromatics Reduction. Inorg. Chem. 2019, 58, 11164-11171. [CrossRef] [PubMed]

23. Wang, F.; Qiao, J.; Wang, J.; Wu, H.; Wang, Z.; Sun, W.; Sun, K. Multimetallic Core-Bishell Ni@Au@Pd nanoparticles with reduced graphene oxide as an efficient bifunctional electrocatalyst for oxygen reduction/evolution reactions. J. Alloys Compd. 2019, 811. [CrossRef]

24. Cano, M.; Villuendas, P.; Benito, A.M.; Urriolabeitia, E.P.; Maser, W.K. Carbon nanotube-supported gold nanoparticles as efficient catalyst for the selective hydrogenation of nitroaromatic derivatives to anilines. Mater. Today Commun. 2015, 3, 104-113. [CrossRef]

25. Glotov, A.; Stavitskaya, A.; Chudakov, Y.; Ivanov, E.; Huang, W.; Vinokurov, V.; Zolotukhina, A.; Maximov, A.; Karakhanov, E.; Lvov, Y. Mesoporous Metal Catalysts Templated on Clay Nanotubes. Bull. Chem. Soc. Jpn. 2019, 92, 61-69. [CrossRef]

26. Jia, L.; Zhou, T.; Xu, J.; Li, F.; Xu, Z.; Zhang, B.; Guo, S.; Shen, X.; Zhang, W. AuPd Bimetallic Nanocrystals Embedded in Magnetic Halloysite Nanotubes: Facile Synthesis and Catalytic Reduction of Nitroaromatic Compounds. Nanomaterials 2017, 7, 333. [CrossRef]

27. Leandro, S.R.; Fernandes, C.I.; Viana, A.S.; Mourato, A.C.; Vaz, P.D.; Nunes, C.D. Catalytic performance of bulk and colloidal $\mathrm{Co} / \mathrm{Al}$ layered double hydroxide with Au nanoparticles in aerobic olefin oxidation. Appl. Catal. A Gen. 2019, 584. [CrossRef]

28. Liu, W.; Sun, D.; Fu, J.; Yuan, R.; Li, Z. Assembly of evenly distributed Au nanoparticles on thiolated reduced graphene oxide as an active and robust catalyst for hydrogenation of 4-nitroarenes. RSC Adv. 2014, 4, 11003-11011. [CrossRef]

29. Rocha, M.; Costa, P.; Sousa, C.A.; Pereira, C.; Rodriguez-Borges, J.E.; Freire, C. 1-serine-functionalized montmorillonite decorated with Au nanoparticles: A new highly efficient catalyst for the reduction of 4-nitrophenol. J. Catal. 2018, 361, 143-155. [CrossRef]

30. Hosseini, S.H.; Zohreh, N.; Alipour, S.; Busuioc, C.; Negrea, R. Gold nanoparticles stabilized on SBA-15 functionalized NNN-pincer ligand; highly effective catalyst for reduction of nitroarenes in aqueous medium. Catal. Commun. 2018, 108, 93-97. [CrossRef]

31. Fan, H.-T.; Liu, X.-G.; Xing, X.-J.; Li, B.; Wang, K.; Chen, S.-T.; Wu, Z.; Qiu, D.-F. Ordered mesoporous silica cubic particles decorated with silver nanoparticles: A highly active and recyclable heterogeneous catalyst for the reduction of 4-nitrophenol. Dalton Trans. 2019, 48, 2692-2700. [CrossRef] [PubMed]

32. Zhao, P.; Feng, X.; Huang, D.; Yang, G.; Astruc, D. Basic concepts and recent advances in nitrophenol reduction by gold- and other transition metal nanoparticles. Coord. Chem. Rev. 2015, 287, 114-136. [CrossRef]

33. Qu, R.; Macino, M.; Iqbal, S.; Gao, X.; He, Q.; Hutchings, G.J.; Sankar, M. Supported Bimetallic AuPd Nanoparticles as a Catalyst for the Selective Hydrogenation of Nitroarenes. Nanomaterials 2018, 8, 690. [CrossRef] [PubMed]

34. Fu, H.; Zhang, L.; Wang, Y.; Chen, S.; Wan, Y. Thermally reduced gold nanocatalysts prepared by the carbonization of ordered mesoporous carbon as a heterogeneous catalyst for the selective reduction of aromatic nitro compounds. J. Catal. 2016, 344, 313-324. [CrossRef]

35. Lokteva Ekaterina, S.; Golubina Elena, V. Metal-support interactions in the design of heterogeneous catalysts for redox processes. Pure Appl. Chem. 2019, 91, 609. [CrossRef] 
36. Shi, H. Valorization of Biomass-derived Small Oxygenates: Kinetics, Mechanisms and Site Requirements of H2-involved Hydrogenation and Deoxygenation Pathways over Heterogeneous Catalysts. ChemCatChem 2019, 11, 1824-1877. [CrossRef]

37. Dong, H.; Xie, R.; Yang, L.; Li, F. A hierarchical flower-like hollow alumina supported bimetallic AuPd nanoparticle catalyst for enhanced solvent-free ethylbenzene oxidation. Dalton Trans. 2018, 47, 7776-7786. [CrossRef]

38. Chen, L.; Yan, J.; Tong, Z.; Yu, S.; Tang, J.; Ou, B.; Yue, L.; Tian, L. Nanofiber-like mesoporous alumina supported palladium nanoparticles as a highly active catalyst for base-free oxidation of benzyl alcohol. Microp. Mesop. Mater. 2018, 266, 126-131. [CrossRef]

39. Nikoofar, K.; Shahedi, Y.; Chenarboo, F.J. Nano Alumina Catalytic Applications in Organic Transformations. Mini Rev. Org. Chem. 2019, 16, 102-110. [CrossRef]

40. Tiwari, J.N.; Tiwari, R.N.; Kim, K.S. Zero-dimensional, one-dimensional, two-dimensional and three-dimensional nanostructured materials for advanced electrochemical energy devices. Prog. Mater. Sci. 2012, 57, 724-803. [CrossRef]

41. Lu, C.L.; Lv, J.G.; Xu, L.; Guo, X.F.; Hou, W.H.; Hu, Y.; Huang, H. Crystalline nanotubes of $\gamma$-AlOOH and $\gamma$-Al2O3: Hydrothermal synthesis, formation mechanism and catalytic performance. Nanotechnology 2009, 20, 215604. [CrossRef]

42. Wang, X.; Perret, N.; Delgado, J.J.; Blanco, G.; Chen, X.; Olmos, C.M.; Bernal, S.; Keane, M.A. Reducible Support Effects in the Gas Phase Hydrogenation of p-Chloronitrobenzene over Gold. J. Phys. Chem. C 2013, 117, 994-1005. [CrossRef]

43. Wang, X.; Perret, N.; Keane, M.A. The role of hydrogen partial pressure in the gas phase hydrogenation of p-chloronitrobenzene over alumina supported Au and Pd: A consideration of reaction thermodynamics and kinetics. Chem. Eng. J. 2012, 210, 103-113. [CrossRef]

44. Yakushkin, S.S.; Nuzhdin, A.L.; Artiukha, E.A.; Plyusnin, P.E.; Bukhtiyarova, G.A.; Martyanov, O.N. In situ EPR study of chemoselective hydrogenation of nitroarenes on $\mathrm{Au} / \mathrm{Al}_{2} \mathrm{O}_{3}$ catalyst. Mendeleev Commun. 2018, 28, 536-537. [CrossRef]

45. Mali, A.C.; Deshmukh, D.G.; Joshi, D.R.; Lad, H.D.; I Patel, P.; Medhane, V.J.; Mathad, V.T. Facile approach for the synthesis of rivaroxaban using alternate synthon: Reaction, crystallization and isolation in single pot to achieve desired yield, quality and crystal form. Sustain. Chem. Process. 2015, 3, 5900. [CrossRef]

46. Gardiner, J.; Nguyen, X.; Genet, C.; Horne, M.D.; Hornung, C.H.; Tsanaktsidis, J. Catalytic Static Mixers for the Continuous Flow Hydrogenation of a Key Intermediate of Linezolid (Zyvox). Org. Process. Res. Dev. 2018, 22, 1448-1452. [CrossRef]

47. Bustamante, T.M.; Dinamarca, R.; Torres, C.C.; Pecchi, G.; Campos, C.H. Pd-Co catalysts prepared from palladium-doped cobalt titanate precursors for chemoselective hydrogenation of halonitroarenes. Mol. Catal. 2019. [CrossRef]

48. Bharath, Y.; Alugubelli, G.R.; Sreenivasulu, R.; Rao, M.V.B. Design, synthesis of novel oxazolidino-amides/ sulfonamides conjugates and their impact on antibacterial activity. Chem. Pap. 2018, 72, 457-468. [CrossRef]

49. Xing, J.; Yang, L.; Li, H.; Li, Q.; Zhao, L.; Wang, X.; Zhang, Y.; Zhou, M.; Zhou, J.; Zhang, H. Identification of anthranilamide derivatives as potential factor Xa inhibitors: Drug design, synthesis and biological evaluation. Eur. J. Med. Chem. 2015, 95, 388-399. [CrossRef]

50. Markgraf, J.H.; Stickney, C.A. A new synthesis of N-phenyl lactams. J. Heterocycl. Chem. 2000, 37, 109-110. [CrossRef]

51. Campos, C.H.; Díaz, C.F.; Guzmán, J.L.; Alderete, J.B.; Torres, C.C.; Jiménez, V.A. PAMAM-Conjugated Alumina Nanotubes as Novel Noncytotoxic Nanocarriers with Enhanced Drug Loading and Releasing Performances. Macromol. Chem. Phys. 2016, 217, 1712-1722. [CrossRef]

52. Dinamarca, R.B.; Espinoza-González, R.; Campos, C.H.; Pecchi, G. Magnetic Pt single and double core-shell structures for the catalytic selective hydrogenation of cinnmaladehyde. Pure Appl. Chem. 2019. [CrossRef]

53. Campos, C.H.; Torres, C.; Fierro, J.L.; Reyes, P. Enantioselective hydrogenation of 1-phenyl-1,2-propanedione over Pt on immobilized cinchonidine on $\gamma-\mathrm{Al}_{2} \mathrm{O}_{3}$ catalysts. Appl. Catal. A Gen. 2013, 466, 198-207. [CrossRef]

54. Liu, W.; Hiekel, K.; Hübner, R.; Sun, H.; Ferancova, A.; Sillanpää, M. Pt and Au bimetallic and monometallic nanostructured amperometric sensors for direct detection of hydrogen peroxide: Influences of bimetallic effect and silica support. Sens. Actuators B Chem. 2018, 255, 1325-1334. [CrossRef] 
55. Bogdanchikova, N.; Pestryakov, A.; Farías, M.; Diaz, J.; Avalos, M.; Navarrete, J. Formation of TEM- and XRD-undetectable gold clusters accompanying big gold particles on $\mathrm{TiO} 2-\mathrm{SiO} 2$ supports. Solid State Sci. 2008, 10, 908-914. [CrossRef]

56. Sobczak, I.; Calvino-Casilda, V.; Wolski, L.; Siodla, T.; Martin-Aranda, R.; Ziolek, M. The role of gold dopant in $\mathrm{AP}-\mathrm{Nb} / \mathrm{MCF}$ and $\mathrm{AP}-\mathrm{MCF}$ on the Knoevenagel condensation of ethyl cyanoacetate with benzaldehyde and 2,4-dichlorobenzaldehyde. Catal. Today 2019, 325, 81-88. [CrossRef]

57. Tuzovskaya, I.; Bogdanchikova, N.; Simakov, A.; Gurin, V.; Pestryakov, A.; Avalos, M.; Farías, M. Structure and electronic states of gold species in mordenites. Chem. Phys. 2007, 338, 23-32. [CrossRef]

58. Zhao, J.; Wang, B.; Yue, Y.; Di, S.; Zhai, Y.; He, H.; Sheng, G.; Lai, H.; Zhu, Y.; Guo, L.; et al. Towards a greener approach for the preparation of highly active gold/carbon catalyst for the hydrochlorination of ethyne. J. Catal. 2018, 365, 153-162. [CrossRef]

59. Wojcieszak, R.; Genet, M.J.; Eloy, P.; Ruiz, P.; Gaigneaux, E.M. Determination of the Size of Supported Pd Nanoparticles by X-ray Photoelectron Spectroscopy. Comparison with X-ray Diffraction, Transmission Electron Microscopy, and H2 Chemisorption Methods. J. Phys. Chem. C 2010, 114, 16677-16684. [CrossRef]

60. Yang, X.; Yang, Z.; Tang, F.; Xu, J.; Zhang, M.; Choi, M.M.F. Structural and optical properties of penicillamine-protected gold nanocluster fractions separated by sequential size-selective fractionation. Beilstein J. Nanotechnol. 2019, 10, 955-966. [CrossRef]

61. Cárdenas-Lizana, F.; Lamey, D.; Gómez-Quero, S.; Perret, N.; Kiwi-Minsker, L.; Keane, M.A. Selective three-phase hydrogenation of aromatic nitro-compounds over $\beta$-molybdenum nitride. Catal. Today 2011, 173, 53-61. [CrossRef]

62. Xiong, H.; Pham, H.N.; Datye, A.K. Hydrothermally stable heterogeneous catalysts for conversion of biorenewables. Green Chem. 2014, 16, 4627-4643. [CrossRef]

63. Sievers, C.; Noda, Y.; Qi, L.; Albuquerque, E.M.; Rioux, R.M.; Scott, S.L. Phenomena Affecting Catalytic Reactions at Solid-Liquid Interfaces. ACS Catal. 2016, 6, 8286-8307. [CrossRef]

64. Furimsky, E. Hydroprocessing in Aqueous Phase. Ind. Eng. Chem. Res. 2013, 52, 17695-17713. [CrossRef]

(C) 2020 by the authors. Licensee MDPI, Basel, Switzerland. This article is an open access article distributed under the terms and conditions of the Creative Commons Attribution (CC BY) license (http://creativecommons.org/licenses/by/4.0/). 